\title{
EFEITOS TERAPÊUTICOS DO DIODO EMISSOR DE LUZ - LED EM MASTITES LACTACIONAIS
}

\section{THERAPEUTIC EFFECTS OF LIGHT EMITTING DIODE (LED) IN LACTACIONAIS MASTITIS}

\author{
Mônica Cristina Melo Santos ${ }^{1}$ \\ Francisco da Costa Gomes Filho ${ }^{2}$ \\ Renata Amadei Nicolau ${ }^{3}$
}

RESUMO: Mastite é o processo inflamatório de um ou mais segmentos da mama, que pode ou não progredir para infecção bacteriana. Suas taxas de ocorrência variam de 4\% a 8,5\% em todas as lactantes; e, os abscessos mamários em $5 \%$ a $11 \%$ dos casos, representando incidência de 0,4 a 0,5\% de todas as lactantes. $O$ tratamento clínico consiste no combate à infecção e no uso de analgésicos. Dentre as formas terapêuticas utilizadas para alívio da dor está a Terapia a Laser de Baixa Intensidade - TLBI; cuja eficácia na redução dos sintomas álgicos tem sido evidenciada por vários autores em diferentes especialidades; isto porque diversas reações teciduais podem ser obtidas; porém a escolha do comprimento de onda, dosagem e tempo de exposição estão relacionadas com alguns fatores intrínsecos da paciente, como nutrição tecidual e sistêmica, idade, e, sexo; o que justifica as diferentes respostas. O Laser possui propriedades que o diferenciam de outras fontes luminosas: monocromaticidade, coerência e colimação; e, como a resposta celular à fotoestimulação não está associada às suas propriedades específicas, como a coerência, permitiu - se o trabalho com fontes emissoras de luz não coerentes, como os Diodos Emissores de Luz - LEDs - dispositivos mais baratos, de fácil manuseio, e que operam com correntes elétricas relativamente baixas em comparação aos laseres. Poucos trabalhos foram realizados com o LED em reparo tecidual, não se observando o emprego desta ferramenta terapêutica em mastites, sendo, portanto, objeto de estudo desta revisão.

Palavras-chave: Terapia Laser de Baixa Intensidade; mastite; laseres; Diodo Emissor de Luz; LED.

ABSTRACT: Mastitis is the inflammation of one or more segments of the breast that may or may not progress to a bacterial infection. Their rates of occurrence vary from $4 \%$ to $8.5 \%$ in all lactatining women, and breast abscesses in $5 \%$ to $11 \%$ of cases, an incidence from 0.4 to $0.5 \%$ in all lactatining women. Clinical treatment is to combat infection and use analgesics. Among the forms of therapy used for pain relief is Low Intensity Laser Therapy - LILT, whose effectiveness in reducing pain symptoms has been noted by several authors in different specialties. The difference responses to LILT are due to different reactions of the tissue. .However, the choice of wavelength, dose, and exposure time are related to intrinsic patient factors such as nutrition and systemic tissue, age, and sex. Laser has properties that differentiate it from other light sources: monochromaticity, coherence, and collimation. Because the cellular response to photic stimulation is not related to its specific properties, consistency light sources such as non-consistent Light emitting diodes (LEDs) can be used, which are less expensive, easier to handle, and operate at relatively low electric currents compared with Lasers. Few studies have been performed with the LED in tissue repair, with no significant employment of this therapeutic tool in mastitis, which is the object of study in this review.

Keywords: Low Intensity Laser Therapy; mastitis; lasers; Light Emitting Diode; LED.

\footnotetext{
${ }^{1}$ Mestranda em Bioengenharia - Universidade do Vale do Paraíba - Univap, Coordenadora da Equipe de Planejamento da Secretaria Municipal de Saúde de Caxias - MA e Professora Titular da Universidade Estadual do Maranhão - UEMA. E-mail: monicacmsantos@gmail.com.

${ }^{2}$ Mestrando em Bioengenharia - Univap, médico da Prefeitura Municipal de Caxias - MA e Professor Auxiliar da UEMA. E-mail: fcgfilho@gmail.com.

${ }^{3}$ Doutora em Engenharia Biomédica - Univap e Professora Titular da Univap. E-mail: rani@univap.br.
} 


\section{INTRODUÇÃO}

As intercorrências mamárias são as principais causas de desmame precoce, por causa da dor, e quando não tratadas a tempo, levam a quadros severos de mastites (conforme Fig. 1), abcessos, e até mesmo septicemia. Pelo caráter emergencial dessas complicações, elas costumam ser atendidas nos Pronto - Socorros ou Bancos de Leite Humano - BLH (FEBRASGO, 2010).

Mastite é o processo inflamatório de um ou mais segmentos da mama (mais comum primeiro quadrante superior esquerdo), que pode ou não progredir para infecção bacteriana. As fissuras são, na maioria das vezes, a porta de entrada das bactérias, ocorrendo comumente na segunda ou terceira semana após o parto, não sendo frequente sua progressão após a $12^{\mathrm{a}}$ semana. O leite acumulado, a resposta inflamatória e o dano tecidual resultante favorecem a instalação da infecção, em geral causada pelo Staphylococcus aureus (ZUGAIB, 2008; POTTER, 2005). A publicação da Organização Mundial da Saúde, intitulada "Causas e Manejo da Mastite Lactacional" (OMS, 2000), destaca que as duas causas principais de mastite são: a estase do leite e a consequente infecção. Ressalta que qualquer fator que predisponha à estagnação do leite no interior das mamas, como, por exemplo: a produção excessiva de leite, o esvaziamento incompleto da mama, a diminuição do número de mamadas, as falhas no procedimento de sucção do bebê e os longos intervalos entre as mamadas, são predisponentes para o desenvolvimento da mastite; apontando, ainda, como fatores de risco para a doença: o uso de chupetas e mamadeiras, fissuras mamilares, episódio anterior de mastite, primiparidade, fadiga da mãe e trabalho fora do lar.

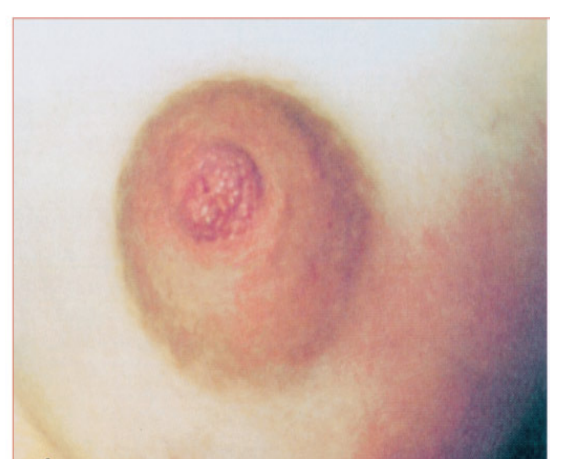

Fig. 1 - Mastite Lactacional. Fonte: ZUGAIB (2008).

Segundo Costa e Rocha (1997), as mastites são classificadas em mastite aguda e mastite crônica, sendo as agudas definidas como processos infecciosos que se instalam nos tecidos mamários na gravidez ou no puerpério (principalmente a partir do $15^{\circ}$ dia pós-parto), embora sejam observadas em qualquer faixa etária e em todas as fases da vida da mulher. Referem, ainda, que a mastite lactacional persiste inalterada com o passar dos anos, variando entre $1 \%$ e $5 \%$ nas mulheres que amamentam; e ainda que, aproximadamente metade dos casos acontece em primíparas. Para a Organização Mundial de Saúde, a mastite ocorre em todas as populações, independente da amamentação na região ser uma regra ou não, variando a incidência até $33 \%$, mas normalmente não sendo superior a 10\% (WHO, 2000). Essa ampla variação na incidência se deve a diferenças nas definições de caso dos vários estudos já realizados, mas a mastite pode ocorrer durante todo o período de aleitamento, sendo mais frequente nos primeiros três meses de aleitamento. Suas taxas de ocorrência variam de $4 \%$ a $8,5 \%$ em todas as lactantes; e a recorrência varia de $14,5 \%$ a $36 \%$ em pacientes que apresentam antecedente de mastite em ciclos gravídicos - puerperais prévios; e, os abscessos mamários ocorrem em $5 \%$ a $11 \%$ dos casos 
de mastite, o que correspondem a uma incidência de 0,4 a $0,5 \%$ de todas as lactantes (BITTAR; ZUGAIB, 2008). Segundo Barros (2000), a mastite no ciclo gravídico puerperal pode estar relacionada com a inexperiência de cuidados, técnicas de enfermagem impróprias, fadiga, estresse, condições de higiene inadequadas, trauma sobre a mama, mamilos planos ou ingurgitados e situações que favoreçam a estase láctea; o que demonstra que muitas complicações mamárias podem ser evitadas quando a gestante tem acesso a um prénatal com qualidade, pois a pega incorreta do mamilo, as mamas ingurgitadas, e as fissuras, muitas vezes, podem ser evitadas por meio de orientações prévias por equipe multidisciplinar. Barbosa-Cesnik, Schwartz e Foxman (2003) descrevem o diagnóstico da mastite a partir da observação dos sinais e sintomas clínicos compatíveis com uma inflamação: dor local, calafrios, mialgia, febre, edema unilateral e eritema circunscrito. $O$ endurecimento de parte da mama, associado à dor, pode ser sugestivo de obstrução dos lóbulos mamários, observando-se, por vezes, hiperemia, turgor e calor na região acima da área de endurecimento.

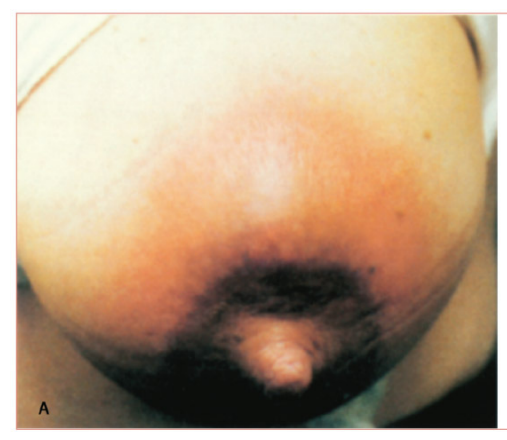

Fig. 2 - Abscesso Mamário Lactacional. Fonte: ZUGAIB (2008).

A analgesia e a antibioticoterapia devem ser precocemente iniciadas para inibir supostas complicações das mastites (THE ACADEMY OF BREASTFEEDING, 2008). Outros autores, como Piato (2007) e Zugaib (2008), afirmam que o tratamento clínico consiste em combater a infecção, devendo a escolha do antibiótico ser adequada ao agente etiológico; sabendo-se que o estafilococo é o principal alvo de combate, uma vez que é o mais frequente agente da doença; e, quando não se dispõe do diagnóstico etiológico preciso, utilizamse, em geral, as cefalosporinas; e, como medidas anti-inflamatórias, incluem-se o uso de analgésicos. A suspensão da lactação não é absolutamente necessária, devendo ser evitada (GIVENS; LUSZCZAK, 2002); e, o uso de compressas frias ou quentes não é recomendado, pelo risco de lesão tecidual sem benefício aparente (MICHIE; LOCKIE; LYNN, 2003). Como tratamento, Barros Jr. e Motolla (1997) acrescentam o cirúrgico reservado aos casos de abscessos bem formados; com anestesia geral, possibilitando a completa abordagem das lojas que normalmente são múltiplas $\mathrm{e}$ profundas, devendo serem instalados drenos conforme apresentação. $\mathrm{E}$ em abscessos mamários menores que $5 \mathrm{~cm}$ e com loja única realiza-se anestesia local com agulha fina, seguida por punção com agulha grossa, guiada por ultrassonografia e acoplada em frasco a vácuo, o que permite aspiração das lojas existentes (ZUGAIB, 2008).

E, dentre as formas terapêuticas utilizadas para alívio da dor está a Laserterapia de Baixa Intensidade - LBI, cuja eficácia na redução dos sintomas álgicos de diversas doenças tem sido evidenciada por diversos autores em diferentes situações e especialidades (GONÇALVES; FILIPINI; POSSO, 2009). A palavra LASER é um acrônimo de Light 
Amplification by Stimulated Emission of Radiation, que significa amplificação da luz por emissão estimulada de radiação (GENOVESE, 2007). O início da utilização do laser em medicina foi acidental, quando um técnico de laboratório teve sua retina queimada pela convergência do raio; e, em virtude da reação frente ao acidente, o primeiro uso do laser foi à soldadura do descolamento da retina, evitando a cegueira total, surgindo suas primeiras aplicações na área da oftalmologia (GOLDMAN, 1990). Nos últimos vinte anos, na busca de novas modalidades terapêuticas menos invasivas e mais eficientes, a irradiação com LBI tem sido amplamente utilizada na prática clínica em função de seus efeitos biomodulatórios.

O laser é formado por um feixe de luz coerente que se concentra numa área pequena, bem definida, e, praticamente não existem dispersão e espalhamento nesse feixe luminoso, ao contrário de uma lâmpada, cujos raios luminosos se espalham abrangendo grande área; e, ainda, qualquer substância no interior desse raio evapora-se instantaneamente.

Segundo Nicolau (2001), o laser possibilita a focalização em pequenas áreas e a emissão de altas densidades de energia, fazendo-o um instrumento de grande interesse e importância para aplicações na área da saúde, tanto no diagnóstico como na terapia. O LASER terapêutico é utilizado desde 1960 e sua aplicação no tratamento de feridas, por exemplo, está ganhando maiores proporções. O LASER e o LED são fontes de luz levemente diferentes (Fig. 3). O LASER é uma fonte de radiação coerente, enquanto que o LED é uma fonte de radiação incoerente, ou seja, o LASER tem uma única cor e um comprimento de onda. Os LEDs emitem luz numa faixa de comprimento de onda e podem oferecer várias opções de emissão de cores. O Diodo Emissor de Luz - LED -, possui várias semelhanças em suas características quando comparado ao LASER, porém, poucos trabalhos foram realizados empregando o LED em reparo tecidual (NICOLAU, 2001; GENOVESE, 2007).

Uma das principais utilizações do LED como tratamento terapêutico é seu auxílio na cicatrização pela aplicação local de luz de comprimentos de onda específicos, potência irradiada e o tempo determinado para aplicação local. O importante é obter o comprimento de onda desejado e a potência suficiente para penetrar nas camadas mais profundas ou superficiais da pele (VINCK et al., 2005). O LED tem uma vantagem clara, oferece várias luzes de cores diferentes (depende do tipo e modelo), podendo ser hermeticamente embalados em conjunto e se sobrepõem uns aos outros para entregar várias cores ou comprimentos de onda simultaneamente em uma considerável área de tecido (NICOLAU, 2001; VINCK et al., 2005). O LASER oferece algumas vantagens como maior potência óptica se comparado com os LEDs: largura espectral menor o que proporciona menor dispersão material e é eficaz em alguns tratamentos (NICOLAU, 2001; VINCK et al., 2005; MOREIRA, 2009). Entre suas desvantagens, é que é mais caro que os LEDs, pois a dificuldade de fabricação é maior; é mais sensível que os LEDs e trabalha somente com comprimentos de onda específicos. Aplicação de LEDs em tecidos humanos é indolor e não causa desconforto no paciente e não é um tratamento traumático, apresenta boa resposta, pois realiza estimulação natural em nível celular. Porém ambos não apresentam coerência dos fótons quando interagem no interior dos tecidos após irradiação (VINCK et al., 2005). 
Por não ter sido observado o uso dessa

se, portanto, objeto de estudo desta revisão. ferramenta terapêutica em mastites, tornou-

\begin{tabular}{lcc}
\hline \multicolumn{1}{c}{ CARACTERISTICAS } & LASER & LED \\
\hline Potência Óptica & Alta & Baixa \\
Custo & Alto & Baixo \\
Utilização & Complexa & Simples \\
Largura do Espectro & Estreita & Larga \\
Tempo de Vida & Menor & Maior \\
Velocidade & Rápido & Lento \\
Divergência de Emissão & Menor & Maior \\
Sensível a Temperatura & Maior & Menor \\
\hline
\end{tabular}

Fig. 3 - Principais diferenças Laser e LED. Fonte: MOREIRA (2009).

Dessa forma, o que se pretende mediante este estudo, é conhecer os efeitos terapêuticos do LED em mastites devido à sua similaridade de características e efeitos com o LASER e sua interação da luz com o tecido humano, assim, o objetivo deste estudo foi identificar a produção científica nacional e internacional relacionada com a Terapia fotodinâmica (TFD) nas mastites.

\section{METODOLOGIA}

Para o desenvolvimento desta revisão, partiu-se de uma questão norteadora: Quais os efeitos terapêuticos do diodo emissor de luz - LED, em mastites lactacionais descritos na literatura? Para tanto, realizaram-se pesquisas nas bases de dados da Biblioteca Eletrônica de Periódicos Científicos Brasileiros - SciELO; Literatura Internacional - MedLine; Literatura Latinoamericana e do Caribe - LILACS; Biblioteca Virtual em Saúde - BVS; e, ainda, no Google Acadêmico. Como descritores, foram utilizados os termos: Laser and Mastitis; Mastites; Diodo Emissor de Luz e Light Emitting Diode - LED; LED and Mastitis; Efeitos Terapêuticos do LED, e, Efeitos Terapêuticos do LASER. Os critérios de inclusão foram: artigos na íntegra, independente da metodologia utilizada e que citem a LBI em mastites. Por se tratar de um item extremamente específico, não se limitou o período, sendo captados artigos entre 2004 a 2009.

\section{RESULTADOS E DISCUSSÃO}

Devido à escassez de artigos pertinentes ao objetivo, ampliou-se a busca, expandindo as bases de pesquisa, incluindo a consulta das referências dos trabalhos selecionados. Assim, na busca isolada do termo "mastite" na BVS, encontraram-se 4931 resultados em português, 784 em inglês, e, 51 em espanhol. Ao se cruzar o termo mastite com Terapia Laser e/ou LED, os resultados eram escassos. O termo LED no LILACS apresentou 21 resultados, mas, quando se estabeleceram limites, como o termo "humano", esses resultados restringiram-se a apenas quatro trabalhos, e, à Mastite, apenas dois guardavam alguma semelhança, pois se tratavam de fissuras mamárias.

Mas, quando ampliou-se a busca e rastreou-se as tendências em sites e 
revistas científicas, aparecem variados estudos das aplicações terapêuticas do laser em tecidos, comprovados nos mais variados estudos, inclusive em mastites lactacionais e fissuras mamilares, para alívio da dor (GONÇALVES; FILIPINI; POSSO, 2009). Além disso, a resposta celular à fotoestimulação não está associada a propriedades específicas da luz laser, como a coerência. Isso permitiu o trabalho com fontes emissoras de luz não coerentes, como os diodos emissores de luz - LEDs. Esses dispositivos são mais baratos, de maior facilidade de manuseio, e operam com correntes elétricas relativamente baixas em comparação aos Laseres (SCHUBERT, 2006).

Para o Ministério da Saúde (BRASIL, 2006), há quatro principais dificuldades com o aleitamento materno no período puerperal, quais sejam: pega incorreta do mamilo; fissuras; mamas ingurgitadas; e, mastite. Todas essas dificuldades proporcionam grande desconforto à puérpera devido às suas principais queixas: dor, desconforto às mamadas, hiperemia, e fissuras; dessas queixas, diversos problemas são ocasionados, desde a abertura de uma porta de entrada para bactérias até a instalação de processos infecciosos, como as mastites e abscesso mamário; e, esse conjunto de sintomas e dificuldades representa as principais causas de desmame precoce.

As intercorrências mamárias são as principais causas de desmame precoce, por causa da dor, e quando não tratadas a tempo, levam a quadros severos de mastites, abscessos, e, até mesmo, septicemia. Pelo caráter emergencial dessas complicações, elas costumam ser atendidas nos Pronto - Socorros ou Bancos de Leite Humano - BLH (FEBRASGO, 2010).
Há grande similaridade entre os autores de livros, quanto ao conceito de mastites lactacionais, sua incidência, e, terapêutica. A conduta para o diagnóstico da mastite é usualmente orientada a partir da anamnese e do exame físico que se baseiam na busca do detalhamento da história clínica, visando à investigação da presença de fatores de risco predisponentes e à observação dos sinais e sintomas sugestivos de infecção. Paralelamente, é indicada a retirada do leite da mama afetada, por ordenha, para cultura e teste de sensibilidade aos antimicrobianos. Embora os procedimentos de diagnóstico bacteriológico não sejam utilizados normalmente na prática, em nosso meio, os resultados dessas culturas fornecem informações substanciais aos pacientes que não responderem à terapêutica inicial, como também, informação para o acompanhamento de infecções nosocomiais (RIPLEY, 1999).

Segundo Brito (2001):

- diagnóstico geralmente é efetuado por meio de anamnese e exame físico. Em casos mais graves, pode-se lançar mão de métodos de imagens como auxiliares. Tanto a ultrassonografia quanto a tomografia computadorizada podem orientar na localização das lojas de pus. A mastite aguda puerperal tem como fatores predisponentes a má formação papilar, primiparidade, hipertrofia mamária com estase lática, fissuras, estresse, técnica incorreta de amamentação $e$ más condições de higiene da mama, que somados ao ingurgitamento $e$ à 
imunodepressão da gravidez, instalam o quadro.

Costa e Rocha (1997) e Bittar e Zugaib (2008) citam que o diagnóstico de mastite é clínico, podendo ser complementado por exames bacteriológicos e radiológicos. Para Barros e Motolla Jr. (1997), o diagnóstico é feito basicamente por parâmetros clínicos de anamnese e exame físico; a história de parto recente, de sintomatologia dolorosa na amamentação e a verificação de sinais inflamatórios na mama são os elementos principais a serem considerados.

O diagnóstico oportuno e a terapêutica precoce são decisivos para a cura da mastite (COSTA; ROCHA, 1997; BITTAR; ZUGAIB, 2008). Na prática, observa-se que muitos casos de infecção não adquiridos em hospital são sensíveis à penicilina. Sabe-se que a mastite puerperal é um dos fatores relacionados ao desmame, e o conhecimento das suas características clínicas e bacteriológicas permite a realização de medidas de intervenção que, quando realizadas de maneira precoce, favorece a redução dos casos novos. É consenso que a terapêutica precoce é fundamental para evitar complicações e possibilitar o tratamento sem internações, sendo a escolha do antimicrobiano mais adequado ao agente etiológico, determinada por intermédio do diagnóstico bacteriológico e testes de sensibilidade (COSTA; ROCHA, 1997; BITTAR; ZUGAIB, 2008).

De acordo com Parizotto e Zorzi (2008), as complicações mamárias são fatores que se destacam como predisponentes associados a não realização do Aleitamento Materno Exclusivo, e dentre elas estão mamilos doloridos, trauma mamilar, ingurgitamento mamário, baixa produção de leite, mastite, abscesso mamário, candidíase, mamilos planos ou invertidos. A Organização Mundial de Saúde (OMS, 2009) discorre que as nutrizes enfrentarão alguns problemas que surgirão durante a amamentação, se não forem diagnosticados e tratados precocemente, podendo até interromper 0 aleitamento materno (OMS, 2009). Foi observado que o número de mamadas diárias era bem menor entre as mulheres com mastite, enquanto que a livre demanda foi identificada com uma frequência duas vezes maior em lactantes sem mastite (OMS, 2009).

Esses resultados corroboram as orientações associadas quanto à prevenção da mastite puerperal que indicam o esvaziamento da mama como uma das medidas a serem adotadas para se evitar o acúmulo de leite e, consequentemente, o ingurgitamento mamário, importante fator de risco para a mastite (PINHEIRO, 2008). Em relação ao tratamento de suporte, antes de iniciar a antibioticoterapia, recomenda-se: o esvaziamento da mama por meio da continuidade da amamentação, massagens locais, ordenha manual ou ordenha mecânica (quatro a seis vezes ao dia), com o objetivo de prevenir o ingurgitamento mamário, assim como, reduzir o risco de formação de abscessos.

Também existem algumas técnicas que utilizam conjuntos de LEDs como terapia de auxílio ou, da própria cura, em pacientes que necessitam de reparo tecidual, tanto no rejuvenescimento das células quanto para a cicatrização. Segundo Siqueira e Nascimento (2004), o emprego de LEDs e/ou Laseres de baixa potência com finalidades terapêuticas vem sendo muito ampliado ao longo dos últimos anos com literatura disponível em sites e em diversas revistas científicas. O reparo tecidual advém de uma intricada interação química para o 
reparo da integridade tecidual, promovendo - equilíbrio fisiológico diretamente relacionado ao comprimento de onda e à densidade de energia, isto é, à dosimetria na FTD. A fotoestimulação causada pela irradiação por LEDs ou laseres de baixa potência apresenta uma série de relatos, tais como: o aumento da taxa de proliferação de células (KARU, 1987); o aumento da taxa de produção de fibroblastos e da síntese de colágenos (VINCK et al., 2005); aumento da taxa de síntese de RNA e DNA (KARU, 1987), síntese de ATP (YU; NAIM; LANZAFAME, 1997); e aumento da vascularização e variações na condução nervosa (VINCK et al., 2005).

A LBI para o controle da dor especificamente nas mastites se dá por meio da bioestimulação, acelerando o processo metabólico celular e favorecendo o potencial regenerativo dos tecidos biológicos, resultando no efeito analgésico (ALFEN, 2004; NES, 2005; GONÇALVES; FILIPINI; POSSO, 2009; SABINO et al., 2011).

Muitos profissionais da saúde utilizam o LED como elemento estimulador de ações biológicas, contudo, os LEDs estão gradativamente substituindo os LASERES por não serem agressivos, serem indolores, de baixo custo, não causarem desconforto ao paciente, e por não se tratar um tratamento traumático, apresenta boa resposta, pois realiza estimulação natural em nível celular, resultando em uma resposta significativa nos tratamentos (BAGNATO; RENOVATO, 2005). Os LASERES oferecem algumas vantagens, como maior potência óptica, se comparados com os LEDs, largura espectral menor o que proporciona menor dispersão material e são eficazes em alguns tratamentos, e entre as suas desvantagens, são mais caros que os
LEDs, pois a dificuldade de fabricação é maior; são mais sensíveis que os LEDs e trabalham somente com comprimentos de onda específicos (BAGNATO; RENOVATO, 2005).

\section{CONCLUSÃO}

Entre os estudos incluídos no presente estudo de revisão, fica patente a necessidade de realização de mais pesquisas sobre o uso de LBI em mastites, pois a escassez na literatura nacional e internacional específica foi nítida. Ressaltase, ainda, que apenas um artigo resultante de dissertação de mestrado e uma dissertação de mestrado enfocam a LBI em fissuras mamárias, e propriamente em mastites não foi encontrada essa terapêutica. Portanto, é necessário que sejam realizadas novas pesquisas e revisões para melhor evidenciar a utilização da LBI em processo feminino tão doloroso.

\section{REFERÊNCIAS}

ALFLEN, T. L. Estudo do efeito da laserterapia de baixa potência no processo de cicatrização de fissuras mamárias em parturientes.[Dissertação] São José dos Campos: Universidade do Vale do Paraíba, 2004.

BAGNATO, M. H. S.; RENOVATO, R. D. De tempos curriculares e suas ressonâncias. In: REUNIÃO ANUAL DA ASSOCIAÇÃO NACIONAL DE PÓS-GRADUAÇÃO E PESQUISA EM EDUCAÇÃO, 28., 2005, Caxambu (MG) Anais... Rio de Janeiro: Anped, 2005. v. 1. p. 325-326.

BARBOSA-CESNIK, C.; SCHWARTZ, K.; FOXMAN, B. Lactation Mastitis. JAMA, v. 289, n. 13, p. 1609-1612, 2003. 
BARROS, A. C.; MOTOLLA JR., J. Mastites. In: HALBE, H.W. Tratado de Ginecologia. 2. ed. São Paulo: Roca, 1997. p.1016-1021.

BARROS, A. C. S. D. A Mastite no Ciclo Gravídico-Puerperal. São Paulo: Atheneu, 2000.

BITTAR, R. E.; ZUGAIB, M. Protocolos Assistenciais da Clínica Obstétrica da Faculdade de Medicina da Universidade de São Paulo. 3. ed. São Paulo: Atheneu, 2008.

BRASIL. MINISTÉRIO DA SAÚDE. PréNatal e Puerpério: Atenção Qualificada e Humanizada. Manual Técnico. Brasília: Ministério da Saúde, 2006.

BRITO, L. M. O. et al. Mastite Aguda Lactacional. Revista do Hospital Universitário UFMA, v. 2, p. 54-56, maio/ago. 2001. Disponível em:

http://www.huufma.br/site/estaticas/revista_h u/pdf/Revista_HU_Ano_II_n_2_2001.pdf. Acesso em: Ago. 2011.

CALIFE, K.; LAGO, T.; LAVRAS, C. C. Atenção à Gestante e à Puérpera no SUS: Manual Técnico do Pré-Natal e Puerpério. São Paulo: Secretaria de Estado da Saúde do Estado de São Paulo, 2010.

COSTA, M. M.; ROCHA, A. C. Processos Inflamatórios da Mama. Revista Brasileira de Mastologia, v. 7, p. 20-34, 1997.

FEBRASGO. Federação Brasileira de Associações de Ginecologia e Obstetrícia. Manual de Aleitamento Materno. São Paulo: FEBRASGO, 2010.

GENOVESE, W. J.; BARREIRA FILHO. J. L. Efeitos Terapêuticos dos Lasers de Baixa Intensidade. In: GENOVESE. Walter João (Org.). Laser de Baixa Intensidade. aplicações terapêutica em odontologia. São Paulo: Livraria e Editora Santos, 2007, Cap. 6, p. 39-46.
GENOVESE, W. J. Laser de Baixa Intensidade: aplicações terapêuticas em odontologia. 2. ed. São Paulo: Santos, 2007.

GIVENS, M.; LUSZCZAK, M. Breast Disorders: a Review for Emergency Physicians. J. Emerg. Med., v. 22, n. 1, p. 59-65, Jan. 2002.

GOLDMAN, L. História do laser em medicina. In: PIMENTA, L. Laser em medicina e biologia. São Paulo: Roca, 1990.

GONÇALVES, S. A.; FILIPINI, R.; POSSO, M. B. S. Dor mamilar durante a amamentação: ação analgésica do laser de baixa intensidade. Revista Dor, v. 10, n. 2, p. 125-129, 2009.

KARU, T. I. Photobiological Fundamentals of Low-Power Therapy. IEEE Journal of Quantum Electronics, v. 23, n. 10, p. 17031717, 1987.

MICHIE, C.; LOCKIE, F.; LYNN, W. The Challenge of Mastitis. Arch. Dis. Child., v. 88, n. 9, p. 818-821, Sep. 2003.

MOREIRA, M. C. Utilização de Conversores Eletrônicos que Alimentam LEDs de Alto Brilho na Aplicação em Tecido Humano e sua Interação Terapêutica. 2009. Tese (Doutorado em Engenharia Elétrica), Universidade Federal de Santa Maria, Santa Maria, 2009.

NES, A. G.; POSSO, M. B. S. Patients with moderate chemotherapy-induced mucositis: pain therapy using low intensity lasers. Int. Nurs. Rev., v. 52, n. 1, p. 68-72, Mar. 2005.

NICOLAU, R. A. Efeito do Laser de Baixa Potência (AsGaAl) em Tecido Ósseo de Rato Submetido à Lesão, Analisado por Histomorfometria Óssea. 2001. Dissertação (Mestrado em Engenharia Biomédica). Universidade do Vale do Paraíba. São José dos Campos, 2001. 
OMS. Organização Mundial de Saúde. 2011.

Mastitis: Causas y Manejo. Genebra:

Departamento de Salud y Desarrollo del

Niño y del Adolescente; OMS, 2000.

OMS. Organização Mundial de Saúde. Razões médicas aceitáveis para uso de substitutos do leite materno. Genebra: OMS, 2009.

PARIZOTTO, J.; ZORZI, N. T. Aleitamento materno: fatores que levam ao desmame precoce no município de Passo Fundo, RS. Mundo da Saúde, São Paulo, v. 32, n. 4, p. 466-474, 2008.

PIATO, S. Ginecologia: diagnóstico e tratamento. São Paulo: Manole, 2007.

PINHEIRO, M. S. Mastite Puerperal e seus Condicionantes na Nutriz Portadora de Staphylococcus Aureus. 2008. 144f. Tese (Doutorado em Saúde da Criança e da Mulher), Fundação Oswaldo Cruz. Rio de Janeiro, 2008.

POTTER, B. A multi-method approach to measuring mastitis incidence. Community Pract., v. 78, n. 5, p. 169-173, 2005.

RIPLEY, D. Mastitis. Prim. Care Update Ob/Gyns, v. 6, n. 3, p. 88-92, 1999.

SABINO, L. G. et al. Experimental evidence and model explanation for cell population characteristics modification when applying sequential photodynamic therapy. Laser Physics Letters (Print), v. 8, p. 239-246,

SCHUBERT, E. Light Emitting Diodes. Cambridge: Cambridge University Press, 2006.

SALES, A. N. et al. Mastite Puerperal: Estudo de Fatores Predisponentes. RBGO, Rio de Janeiro, v. 22 , n. 10, p. 627-632, 2000 .

THE ACADEMY OF BREASTFEEDING MEDICINE PROTOCOL COMMITTEE. ABM

Protocols. ABM Clinical Protocol \#4: Mastitis. Breastfeeding Medicine, v. 3, n. 3, p. 177180, 2008.

SIQUEIRA, F.; NASCIMENTO, C. Uso de Laser de Baixa Intensidade em Pacientes com Úlceras de Pressão. São Paulo: Reabilitar, 2004.

VINCK, E. et al. Evidence of changes in sural nerve conduction mediated by light emitting diode irradiation. Lasers Med. Sci., v. 20, n. 1, p. 35-40, May 2005.

WORLD HEALTH ORGANIZATION. Mastitis: causes and management. Geneva: Department of Child and Adolescent; WHO, 2000 .

YU, W.; NAIM, J. O.; LANZAFAME, R. J. Effects of photostimulation on wound healing in diabetic mice. Lasers Surg. Med., v. 20, n. 1, p. 56-63, 1997.

ZUGAIB, M. Obstetrícia. São Paulo: Manole, 2008. 